\title{
Short-term mortality of myocardial infarction patients with diabetes or hyperglycaemia during admission
}

\author{
J Sala, R Masiá, F-J González de Molina, J M Fernández-Real, M Gil, D Bosch, \\ W Ricart, M Sentí, J Marrugat, for the REGICOR Investigators
}

J Epidemiol Community Health 2002;56:707-712

See end of article for authors' affiliations

.....................

Correspondence to: Dr J Marrugat, Unitat de Lipids i Epidemiologia Cardiovascular, Institut Municipal d'Investigació Mèdica (IMIM), Carrer Dr. Aiguader, 80, E-08003

Barcelona, Spain; jmarrugat@imim.es

Accepted for publication 23 November 2001

\begin{abstract}
Aim: The hypothesis that patients with hyperglycaemia during admission, regardless of previous diagnosis of diabetes, have worse prognosis than those with normal glucose values is controversial. The objective was to assess the role of hyperglycaemia on short-term mortality after myocardial infarction (MI).

Methods and Results: A cohort study nested in a prospective registry of $\mathrm{Ml}$ patients in the reference hospital of Gerona, Spain was performed. All consecutive Ml patients under 75 were registered between 1993 and 1996. Patient and clinical characteristics, including previous diagnosis of diabetes, glycaemia on admission and in the next four days, were recorded. Patients with glycaemia on admission or four day mean glycaemia $>6.67 \mathrm{mmol} / \mathrm{l}$ were considered hyperglycaemic. The main outcome measure was mortality at 28 days. Of 662 patients with MI included, 195 (29.7\%) had previously known diabetes mellitus, but 457 (69.0\%) had glycaemia $>6.67 \mathrm{mmol} / \mathrm{l}$ on admission. Patients with hyperglycaemia on admission were older, more often female, more frequently had a previous diagnosis of diabetes, developed more complications, and had higher 28 day mortality. The effect of admission glycaemia $>6.67 \mathrm{mmol} / \mathrm{I}$ on 28 day mortality was independent of major confounding factors, particularly previous diagnosis of diabetes $(O R=4.20,95 \%$ confidence intervals 1.18 to 14.96).

Conclusions: Higher 28 day mortality was observed among MI patients with glycaemia on admission $>6.67 \mathrm{mmol} / \mathrm{l}$ compared with patients with lower levels, independently of major confounding variables and, particularly, previous diagnosis of diabetes. This early, simple, and inexpensive marker of bad prognosis after $\mathrm{Ml}$ should prompt the application of more aggressive treatment of $\mathrm{Ml}$ and risk factors and, probably, of glycaemia during admission.
\end{abstract}


Table 1 Characteristics of myocardial infarction patients by admission glycaemia levels in the REGICOR study (Gerona, Spain, 1993-96)

\begin{tabular}{|c|c|c|c|c|c|c|c|c|c|}
\hline & $\begin{array}{l}\text { Glycaemia } \\
\leqslant 6.67 \\
\text { mmol/I on } \\
\text { admission }\end{array}$ & $\begin{array}{l}\text { Glycaemia } \\
>6.67 \\
\mathrm{mmol} / \mathrm{I} \text { on } \\
\text { admission }\end{array}$ & $\mathrm{p}$ Value & $\begin{array}{l}\text { Four day } \\
\text { mean } \\
\text { glycaemia } \\
\leqslant 6.67 \\
\mathrm{mmol} / \mathrm{l}\end{array}$ & $\begin{array}{l}\text { Four day } \\
\text { mean } \\
\text { glycaemia } \\
>6.67 \\
\mathrm{mmol} / \mathrm{l}\end{array}$ & $\mathrm{p}$ Value & $\begin{array}{l}\text { Without } \\
\text { previous } \\
\text { diagnosis of } \\
\text { diabetes }\end{array}$ & $\begin{array}{l}\text { Previous } \\
\text { diagnosis of } \\
\text { diabetes }\end{array}$ & p Value \\
\hline Number of patients & 205 & 457 & & 242 & 362 & & 445 & 195 & \\
\hline $\mathrm{Age}^{*}$ & $57.7(11.4)$ & $62.7(9.4)$ & $<0.001$ & $58.8(11.5)$ & $62.7(9.3)$ & $<0.001$ & $64.3(8.4)$ & $60.1(10.7)$ & $<0.001$ \\
\hline Women (\%) & 9.3 & 22.8 & $<0.001$ & 12.4 & 23.5 & $<0.001$ & 13.0 & 31.8 & $<0.001$ \\
\hline Hypertension & 43.7 & 47.4 & NS & 43.4 & 46.6 & NS & 42.4 & 53.9 & 0.007 \\
\hline Smoking & 52.2 & 41.9 & 0.013 & 51.3 & 40.7 & 0.011 & 30.7 & 51.4 & $<0.0001$ \\
\hline Diabetes & 8.2 & 40.3 & $<0.001 \dagger$ & 8.5 & 45.1 & $<0.001$ & & & \\
\hline History of angina & 54.4 & 47.7 & 0.111 & 50.8 & 47.1 & NS & 47.1 & 56.7 & 0.025 \\
\hline History of heart failure & 6.9 & 12.3 & 0.035 & 7.9 & 12.8 & 0.061 & 8.6 & 16.5 & 0.003 \\
\hline Previous myocardial infarction & 1.9 & 2.9 & NS & 1.7 & 3.6 & NS & 1.5 & 3.1 & NS \\
\hline Arrhythmias $\ddagger$ & 15.1 & 25.1 & 0.005 & 17.6 & 24.4 & 0.049 & 21.2 & 24.5 & NS \\
\hline Anterior myocardial infarction & 32.8 & 35.0 & NS & 30.8 & 35.4 & NS & 34.7 & 33.9 & NS \\
\hline $\begin{array}{l}\text { Non- } Q \text { wave myocardial } \\
\text { infarction }\end{array}$ & 18.7 & 18.1 & NS & 18.8 & 17.8 & NS & 17.4 & 21.1 & NS \\
\hline $\begin{array}{l}\text { Angina post myocardial } \\
\text { infarction }\end{array}$ & 25.9 & 25.0 & NS & 22.2 & 28.1 & 0.123 & 24.4 & 27.9 & NS \\
\hline 28 day re-infarction & 2.7 & 2.7 & NS & 2.8 & 2.5 & NS & 1.5 & 5.6 & 0.006 \\
\hline $\begin{array}{l}28 \text { day APE or cardiogenic } \\
\text { shock }\end{array}$ & 4.9 & 18.4 & $<0.001$ & 4.6 & 20.2 & $<0.001$ & 8.8 & 25.1 & $<0.001$ \\
\hline 28 day mortality & 1.5 & 10.3 & $<0.001$ & 1.7 & 9.1 & $<0.001$ & 5.4 & 12.3 & 0.002 \\
\hline Thrombolysis & 34.0 & 38.3 & NS & 40.4 & 37.0 & NS & 41.6 & 27.3 & $<0.001$ \\
\hline Antiplatelet drugs & 98.0 & 96.5 & NS & 98.8 & 97.0 & 0.154 & 97.5 & 96.4 & NS \\
\hline 28 day coronary angiograms & 19.5 & 17.4 & NS & 17.5 & 18.3 & NS & 17.0 & 20.8 & NS \\
\hline
\end{tabular}

\begin{tabular}{|c|c|c|c|}
\hline & $\begin{array}{l}\text { Deceased } \\
n=50\end{array}$ & $\begin{array}{l}\text { Survivors } \\
\mathrm{n}=612\end{array}$ & $\mathrm{p}$ Value \\
\hline Age $^{*}$ & $63.1(10.4)$ & $61.0(10.3)$ & NS \\
\hline Women & $28.0 \%$ & $17.8 \%$ & 0.075 \\
\hline Hypertension & $44.9 \%$ & $46.4 \%$ & NS \\
\hline Diabetes & $50.0 \%$ & $28.9 \%$ & 0.002 \\
\hline Smoking & $29.2 \%$ & $46.4 \%$ & 0.021 \\
\hline Glycaemia $>6.67 \mathrm{mmol} / \mathrm{l}$ on admission & $94.0 \%$ & $67.0 \%$ & $<0.001$ \\
\hline Four day mean glycaemia $>6.67 \mathrm{mmol} / \mathrm{l}$ & $89.2 \%$ & $58.0 \%$ & $<0.001$ \\
\hline History of angina & $60.0 \%$ & $48.9 \%$ & 0.132 \\
\hline Previous myocardial infarction & $4.0 \%$ & $2.5 \%$ & NS \\
\hline History of heart failure & $28.0 \%$ & $9.2 \%$ & $<0.0001$ \\
\hline Post myocardial infarction angina & $17.4 \%$ & $26.0 \%$ & NS \\
\hline Arrhythmias $\dagger$ & $52.1 \%$ & $19.6 \%$ & $<0.0001$ \\
\hline Anterior myocardial infarction & $59.5 \%$ & $32.5 \%$ & 0.001 \\
\hline Non-Q wave myocardial infarction & $16.7 \%$ & $18.4 \%$ & NS \\
\hline APE or cardiogenic shock & $71.4 \%$ & $9.7 \%$ & $<0.001$ \\
\hline 28 day re-infarction & $4.2 \%$ & $2.6 \%$ & NS \\
\hline \multicolumn{4}{|l|}{ Therapeutic and diagnostic procedures } \\
\hline Thrombolysis & $14.0 \%$ & $38.9 \%$ & $<0.001$ \\
\hline Antiplatelet drugs & $86.0 \%$ & $97.9 \%$ & $<0.001$ \\
\hline 28 day coronary angiograms & $8.2 \%$ & $18.8 \%$ & 0.062 \\
\hline
\end{tabular}

risks for hyperglycaemia greater than or equal to 2.1 as statistically significant $(\mathrm{p}<0.05)$. Primary end point was 28 day mortality.

\section{Study variables measured in the acute phase of $\mathrm{MI}$}

The following variables were recorded: demographics, history of hypertension, diabetes mellitus with a questionnaire that included questions on previous diagnosis by a physician and treatment for diabetes, MI location, presence of Q waves on electrocardiogram, development of acute pulmonary oedema or cardiogenic shock, presence of severe arrhythmia (defined as the occurrence of at least one episode of ventricular fibrilla- tion or sustained ventricular tachycardia requiring immediate medical intervention) within the first 72 hours, use of thrombolysis, and coronary angiography. As this was a retrospective analysis of a prospective registry, only standard measures of hyperglycaemia management in the acute phase of AMI during hospital admission were recorded. Intensive management of hyperglycaemia was not a practice at the time of inclusion in the registry.

Glycaemia on admission before any treatment or infusion were started, and successive basal glycaemias in samples obtained after eight hour fasting were determined in the following four days. When at least two fasting glucose 


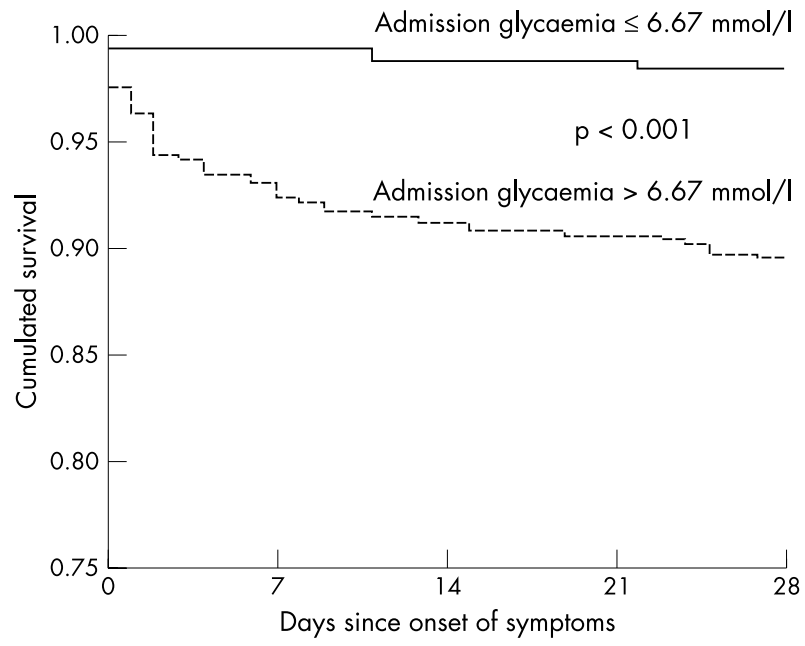

Figure 1 Unadjusted 28 day survival by glycaemia levels on admission after Ml in the REGICOR Study (Gerona, Spain, 1993-96).

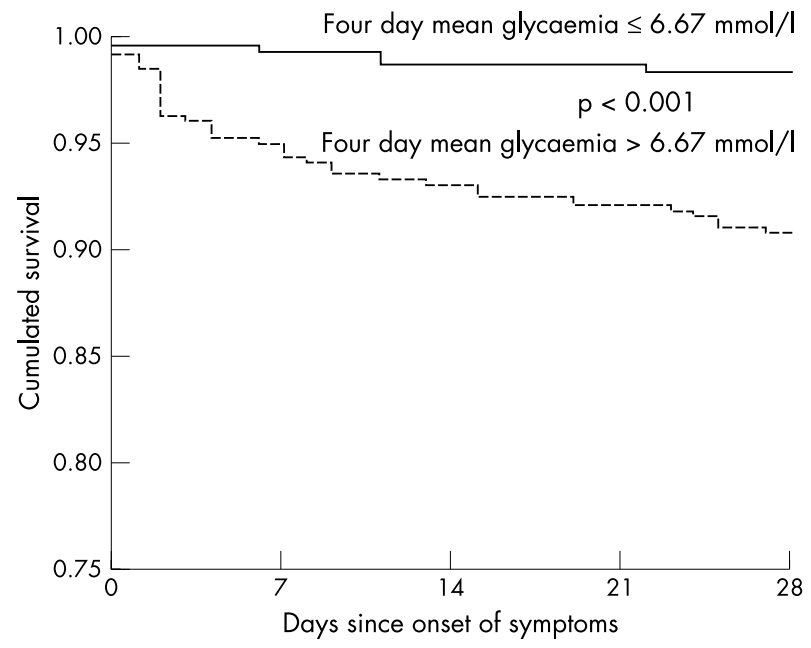

Figure 2 Unadjusted 28 day survival by glycaemia levels during the first four days of admission after MI in the REGICOR Study (Gerona, Spain, 1993-96).

determinations existed after that made on admission, a mean was calculated and used as a predictor of mortality.

\section{Statistical analysis}

Differences between hyperglycaemic patients and the rest were assessed with the $\chi^{2}$ test for categorical variables and Student's $t$ test or Mann-Whitney $U$ test as appropriate for continuous variables.

Receiver operating characteristic curves were used to establish the optimum cut off value for admission and four day mean glycaemias to obtain a sensitivity higher than $90 \%$, using several cut off points (that is, from $5.55 \mathrm{mmol} / \mathrm{l}$ to $11.1 \mathrm{l}$ $\mathrm{mmol} / \mathrm{l}$ every $0.55 \mathrm{mmol} / \mathrm{l}$ ).

Concordance between the diagnosis of diabetes and presence of hyperglycaemia on admission and mean four day hyperglycaemia was calculated by $\kappa$ statistics.

Survival curves were estimated with the Kaplan-Meier method and compared between hyperglycaemic and nonhyperglycaemic patients by Mantel-Cox test. Adjusted relative risks for 28 day mortality were estimated using unconditional logistic regression. To control for differential characteristics between hyperglycaemic patients and the rest, all variables that met confounding factor criteria (that is, factors that statistically differed at an $\alpha$ risk level of 0.05 in bivariate analysis between categories of previous diagnosis of diabetes, glycaemia $>6.67 \mathrm{mmol} / \mathrm{l}$ on admission and mean admission glycaemia $>6.67 \mathrm{mmol} / \mathrm{l}$, and were further associated with mortality but could not be claimed as mechanisms of death) were included in the models together with age and sex.

\section{RESULTS}

Seven hundred and forty two patients were included in the registry between 1993 and 1996. Eighty patients (10.9\%) with suspected MI who died on admission before a glycaemia determination was possible were excluded. Of the 662 patients left for analysis, 195 (29.7\%) had previously known diabetes mellitus (6.9\% type I and $22.9 \%$ type II), but 457 (69.0\%) had glycaemia above $6.67 \mathrm{mmol} / \mathrm{l}$ on admission. Among the 604 patients who had at least two glycaemia measurements within four days after admission, 362 (59.9\%) had mean glycaemia during admission above $6.67 \mathrm{mmol} / \mathrm{l}$. No patient was lost to follow up.

Patients previously diagnosed of diabetes had higher admission and mean four day glycaemias than non-diabetic patients ( $14.06 \mathrm{mmol} / \mathrm{l}$ standard deviation (SD) $7.89 \mathrm{mmol} / \mathrm{l}$ and 7.83 SD 3.05, and 11.67 SD 5.00 and 7.05 SD 2.22, respectively). Glycaemia was above $6.67 \mathrm{mmol} / \mathrm{l}$ in $192(47.3 \%)$ patients previously undiagnosed with diabetes and in 167 $(69.8 \%)$ with diabetes.

\section{Variables associated with hyperglycaemia on admission (>6.67 $\mathrm{mmol} / \mathrm{l}$ )}

Compared with the rest, patients with hyperglycaemia on admission were older, were more often female, more frequently had a previous diagnosis of diabetes, and developed acute pulmonary oedema or cardiogenic shock and severe ventricular arrhythmias. Mortality at 28 days was significantly higher in patients with hyperglycaemia on admission (table 1). Kaplan-Meier survival curves showed a large difference in survival between patients with and without hyperglycaemia on admission (fig l), between patients with and without mean four day hyperglycaemia (fig 2), between patients with and without previous diagnosis of diabetes (table 2 ).

In 604 patients with more than two measurements within the four days after onset of symptoms, concordance between glycaemia on admission and mean of the subsequent glycaemias was high $(\kappa=0.65)$; correlation coefficient was 0.88 $(p<0.001)$. However, concordances of admission glycaemia $>6.67 \mathrm{mmol} / \mathrm{l}$ with previous diagnosis of diabetes $(\kappa=0.25)$ and with mean four day glycaemia $>6.67 \mathrm{mmol} / \mathrm{l}(\kappa=0.4 \mathrm{l})$ were low. Thrombolysis, antiplatelet drugs, and coronary angiography were similarly used in all types of patients. The effect of hyperglycaemia in patients with and without history of diabetes was similar: patients with glycaemias $>6.67$ $\mathrm{mmol} / \mathrm{l}$ had worse outcome in both groups (table 1 ).

\section{Variables associated with mortality}

Compared with deceased patients, 28 day survivors were younger, less frequently had a previous diagnosis of diabetes and heart failure and less often presented severe ventricular arrhythmias, anterior MI, acute pulmonary oedema, or cardiogenic shock. However, a greater proportion of non-Q wave MI was observed. Thrombolysis, antiplatelet drugs, and coronary angiography were more often used in survivors (table 2).

Glycaemia >6.67 mmol/l was associated with higher mortality in patients who were not previously diagnosed of diabetes $(8.5 \%$ versus $1.1 \%, \mathrm{p}<0.001)$. Although in patients with previous diagnosis of diabetes the difference in 28 day mortality was high $(6.3 \%$ versus $12.8 \%)$ it did not reach statistical significance. However, only one of 16 patients previously diagnosed with diabetes with admission glycaemia $\leqslant 6.67 \mathrm{mmol} / \mathrm{l}$ died within 28 days (fig 3 ). 

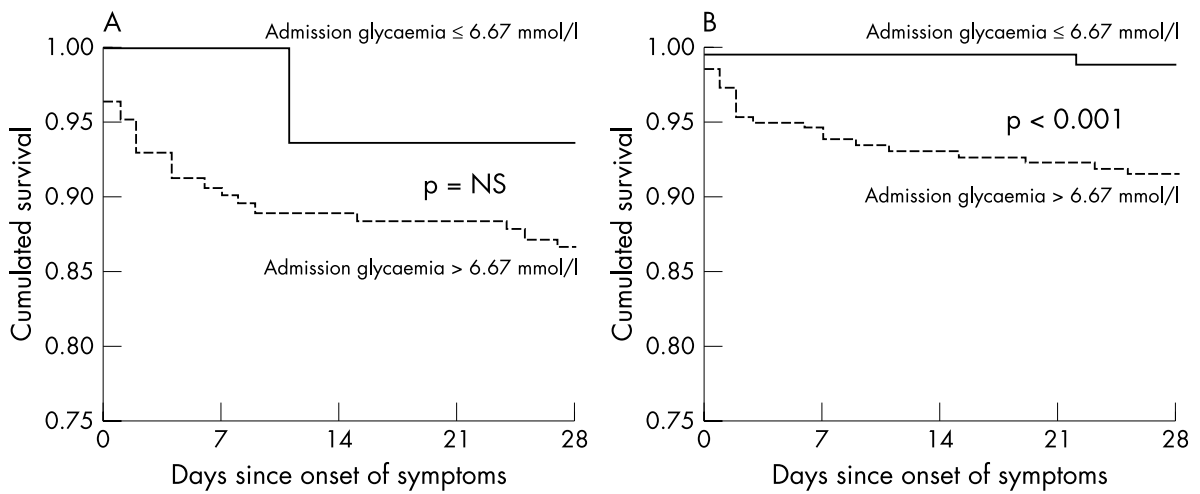

Figure 3 Unadjusted 28 day survival after Ml by glycaemia levels on admission in patients with (panel A) and without previous diagnosis (panel B) of diabetes in the REGICOR Study (Gerona, Spain, 1993-96).

Table 3 Adjusted relative risks (RR) and $95 \%$ confidence intervals (CI) of 28 day mortality after myocardial infarction for patients with previous diagnosis of diabetes, admission glycaemia $>6.67 \mathrm{mmol} / \mathrm{l}$, and mean glycaemia $>6.67$ $\mathrm{mmol} / \mathrm{l}$, in the REGICOR Study (Gerona, Spain, 1993-96)

\begin{tabular}{llll}
\hline & \multicolumn{2}{l}{ Adjusted RR (95\% Cl) } & \\
\cline { 2 - 4 } & Model 1 & Model 2 & Model 3 \\
\hline (A) Previous diagnosis of diabetes & $1.93(1.04$ to 3.58$)$ & $0.99(0.47$ to 2.06$)$ & - \\
(B) Glycaemia $>6.67 \mathrm{mmol} / \mathrm{I}$ on admission & $7.66(2.32$ to 25.30$)$ & $4.13(1.18$ to 14.41$)$ & $4.63(1.29$ to 16.58$)$ \\
(C) Mean admission glycaemia $>6.67 \mathrm{mmol} / \mathrm{I}$ & $5.39(1.86$ to 15.66$)$ & $2.88(0.90$ to 9.17$)$ & $3.15(0.95$ to 10.51$)$ \\
\hline
\end{tabular}

Model 1 adjusted for age, sex, smoking, and thrombolytic treatment (A, B, and C). Model 2 adjusted as model 1 and for history of heart failure, occurrence of cardiogenic shock or acute pulmonary oedema during admission ( $A, B$, and $C$ ), and for the presence of severe arrhythmias (ventricular fibrillation or ventricular tachycardia requiring immediate medical intervention) during first 72 hours of hospital stay ( $B$ and $C)$. Model 3 adjusted as model 2 and for previous diagnosis of diabetes $(\mathrm{B}$ and $\mathrm{C})$.

\section{Adjusted risk of 28 day death}

As shown in table 3, previous diagnosis of diabetes was independently associated with worse 28 day mortality (Model A- 1 : $R R=1.93, p=0.04$ ), which was mostly explained by occurrence of cardiogenic shock or acute pulmonary oedema and severe ventricular arrhythmias (Model A-2: $R R=0.99$, nonstatistically significant). The effect of glycaemia above 6.67 $\mathrm{mmol} / \mathrm{l}$ on admission on 28 day mortality was independent of comorbidity, severity, coronary risk factors and previous diagnosis of diabetes (Model B-3: $R R=4.63 \mathrm{p}<0.001$ ). The risk of 28 day mortality was higher in patients with mean four day hyperglycaemia than in those without (Model C-1 in table 3), but the main reason for the higher mortality was again the occurrence of cardiogenic shock or acute pulmonary oedema, or severe ventricular arrhythmias (model 2 in table 3 ).

\section{DISCUSSION}

Hyperglycaemia independently of diabetic status is a well known predictor of cardiovascular disease and its progression, resulting in increased mortality in the long term. It was first shown by the Whitehall Study, ${ }^{11}$ and by the Rancho Bernardo Study. ${ }^{12}$ It is becoming increasingly clear from recent studies that the glucose level is a lineal risk factor in diabetic and non-diabetic subjects in a fashion similar to others (blood pressure, blood cholesterol), without a definite threshold. ${ }^{13-15}$ In a recent meta-analysis of several studies including more than 95000 patients, hyperglycaemia, below the accepted diabetic threshold, was associated with increased risk of cardiovascular events. ${ }^{6}$

Hyperglycaemia is also a common finding in patients with acute MI and likewise has been found to be an independent predictor of early cardiovascular death. ${ }^{17-19}$ The risk of early death after MI in diabetic patients found in this study (RR 1.98 ) is close to that described in recent revisions. ${ }^{20}{ }^{21}$ We found that plasma glucose above $6.67 \mathrm{mmol} / \mathrm{l}$ optimised sensitivity (96\%) for 28 day mortality prediction. This cut off provides an early, simple, and inexpensive marker of bad prognosis independently of whether or not stress hyperglycaemia is a marker of MI damage. This association is independent of and stronger than previous diagnosis of diabetes. Whether this merely represents a stress response or is, in fact, a harbinger of diabetes remains to be formally established. Approximately $20 \%$ of patients with admission hyperglycaemia (admission plasma glucose levels $>1.11 \mathrm{mmol} / \mathrm{l}$ ) have previously undiagnosed diabetes. ${ }^{22}$ It must be emphasised that this cut off point was selected after it was found to have the strongest association with 28 day mortality and that it was not pre-established when patients were registered in the study or when the data were analysed. This may explain the differences in the glucose levels used in various studies to define hyperglycaemia, even though the differences found in mortality are similar. A recent review includes 16 studies using values ranging between 6.7 and $11 \mathrm{mmol} / \mathrm{l}^{21} \mathrm{It}$ is very remarkable the fact, clear from the previous observations, that there is no universal agreement on the glucose values in the acute phase in relation to diabetes and hyperglycaemia and, consequently, the degree of risk associated with it.

Several mechanisms may explain the role of hyperglycaemia in this setting. Plasma noradrenalin and cortisol concentrations increase in the acute phase of MI and trigger a non-specific stress reaction leading to an impaired plasma insulin response resulting in hyperglycaemia. ${ }^{23}{ }^{24}$ Independently of the cause of hyperglycaemia, there is evidence for toxic effects of high blood glucose levels on cell function. Acute hyperglycaemia has been found to induce oxidative stress, probably via generation of free radicals. ${ }^{25}$ This may occur by auto-oxidation of glucose, labile glycation, or intracellular activation of the polyol pathway. The free radicals may then mediate some of the effects associated with hyperglycaemia such as vasoconstriction through NO decrease, activation of coagulation, and increased expression of adhesion molecules.$^{26}$ Increased glucose levels can also increase protein 
kinase $\mathrm{C}$ activity. ${ }^{27}$ This is an immediate effect of hyperglycaemia, although there is evidence to suggest that the effect of hyperglycaemia may persist for some time after blood glucose levels return to normal. ${ }^{28}$ Various cellular changes associated with this acute hyperglycaemia are probably mediated via protein kinase $\mathrm{C}$ activity, for example, increased endothelin secretion, increased collagen IV and fibronectine secretion and also increased expression of adhesion molecules on the vascular endothelium involved in macrophage migration. ${ }^{29} 30$

Other than cellular toxicity, it has been shown that hyperglycaemia has deleterious effects on endothelium dependent vasodilatation, ${ }^{31}$ worsening myocardial ischaemia, and that treatment with insulin attenuates these effects. Furthermore, basal fibrinolytic activity is diminished in diabetics ${ }^{32}$ and the excess of insulin present in diabetes type II patients increases plasminogen activator inhibitor l (PAI 1), also causing a decrease of fibrinolytic activity. Thus, an accentuation of ischaemia and an increase of thrombogenicity contribute to a greater severity of MI in hyperglycaemic patients.

\section{Study characteristics and clinical implications}

Non-fasting sampling could be claimed to have been responsible for some glycaemias over $6.67 \mathrm{mmol} / \mathrm{l}$ on admission. However, successive determinations were obtained after eight hour fasting and yielded results similar to those obtained with admission blood sample, as shown by the excellent concordance found between them. The number of subsequent determinations decreased as some patients died early after admission. This contributed to decreasing somewhat the intensity of the association between four day mean fasting glycaemia and mortality in 24 hour survivors.

All factors that may confound the relation between glycaemia levels and 28 day case fatality (that is, severity, comorbidity, age, sex and, particularly, previous diagnosis of diabetes) were adjusted for in a logistic model. Therefore, admission glucose concentration is a powerful predictor of early mortality after MI, regardless of any other consideration. Glycosylated haemoglobin was not determined, which constitutes a limitation of the study.

This study shows that many patients who met diabetes criteria according to their admission and four day glycaemia measurements during admission had not been previously diagnosed. It should be emphasised that these were consecutive patients of a general population, including diabetics and non-diabetics. Furthermore, hyperglycaemia on admission was associated with higher 28 day mortality independently of previous diagnosis of diabetes and was a stronger predictor of outcome. This suggests that management of hyperglycaemia during the acute phase of MI could be a major issue requiring further investigation and could be important for future therapeutic approaches. In fact, only the DIGAMI MI trial showed the benefit of treating diabetic patients with pump insulin infusion. ${ }^{33}{ }^{34}$ In this Scandinavian trial, one year mortality was significantly reduced by $25 \%$ in MI patients assigned to aggressive plasma insulin lowering treatment compared with those who were not. Appropriate control of glycaemia might have a large impact on mortality since more than half of MI patients display glycaemia values over $6.67 \mathrm{mmol} / \mathrm{l}$. Moreover, a more aggressive approach to controlling glycaemia could be adopted, at least in MI patients with glycaemia $>6.67 \mathrm{mmol} / \mathrm{l}$ on admission in an attempt to reduce case fatality, given the fact that mortality is not concentrated in the first days after onset of symptoms. Glucose-insulin-potassium studies offer an interesting field of research that might help to mitigate the deleterious effects of hyperglycaemia. ${ }^{35} 36$

Admission glycaemia is an early, simple, and inexpensive marker of bad prognosis after MI. As suggested by other authors, this marker should prompt the clinician to apply more aggressive management of MI, risk factors and, probably, admission glycaemia, in these patients. ${ }^{37} 38$

\section{Key points}

- A glycaemia concentration $>6.67 \mathrm{mmol} / \mathrm{l}$ on admission and during hospital stay is found in most patients with $\mathrm{MI}$.

- Many patients may have unrecognised diabetes mellitus at the time of presenting to the hospital with $\mathrm{Ml}$.

- Ml patients with a glycaemia $>6.67 \mathrm{mmol} / \mathrm{I}$ on admission are at high mortality risk regardless of any other characteristic.

- In consequence, such a finding should prompt the application of more aggressive treatment of $\mathrm{Ml}$ and risk factors.

Our data support the idea that higher 28 day mortality exists among MI patients younger than 75 years with admission glycaemia $>6.67 \mathrm{mmol} / \mathrm{l}$ compared with patients with lower levels, independently of major confounding variables, particularly previous diagnosis of diabetes. Whether this is only an epiphenomenon or an effect of glucose toxicity that worsens myocardial injury remains to be elucidated.

\section{ACKNOWLEDGEMENTS}

We appreciate the English revision of the manuscript made by Christine O'Hara.

\section{Authors' affiliations}

J Sala, D Bosch, F-Jr Gonzalez de Molina, R Masiá, Servei de Cardiologia i Unitat Coronària, Hospital de Girona Josep Trueta, Girona, Spain

J M Fernández-Real, W Ricart, Servei d'Endocrinologia, Hospital de Girona Josep Trueta, Girona, Spain

M Gil, M Sentí, J Marrugat, Unitat de Lipids i Epidemiologia

Cardiovascular, Institut Municipal d'Investigació Mèdica (IMIM),

Barcelona, Spain

Funding: this project was supported by grants $96 / 0026-01$ from the Fondo de Investigación Sanitaria and received partial support through grant CIRIT/1999 SGR 00243 of the Generalitat de Catalunya.

Conflicts of interest: none.

\section{REFERENCES}

1 Laakso $M$, Lehto S. Epidemiology of macrovascular disease in diabetes. Diabetes Reviews 1997:5:294-315.

2 Malmberg K, Ryden L. Myocardial infarction in patients with diabetes mellitus. Eur Heart J 1988;9:259-64.

3 Abbud ZA, Shindler D, Wilson A, et al, for the Myocardial Infarction Data Acquisition System Study Group. Effect of diabetes mellitus on short-and long-term mortality rates of patients with acute myocardial infarction: a statewide study. Am Heart J 1995;130:51-8.

4 Tansey MJ, Opie LH. Plasma glucose on admission to hospital as a metabolic index of the severity of acute myocardial infarction. Can $J$ Cardiol 1986;2:326-31.

5 Norhammar AM, Ryden L, Malmberg K. Admission plasma glucose. Independent risk factor for long-term prognosis after myocardial infarction even in nondiabetic patients. Diabetes Care 1999;22:1827-31

6 Oswald GA, Corcoran S, Yudkin JS. Prevalence and risks of hyperglycaemia and undiagnosed diabetes in patients with acute myocardial infarction. Lancet 1984;i:1264-7.

7 Sala J, Marrugat, Masiá R, et al, and the REGICOR investigators. Improvement in survival after myocardial infarction between 1978-85 and 1986-88 in the REGICOR study. Eur Heart J 1995; 16:779-84.

8 Gil M, Marrugat J, Sala J, et al, and the REGICOR investigators Relationship of therapeutic improvements and 28-day case fatality in patients hospitalized with acute myocardial infarction between 1978 and 1993 in the REGICOR study. Circulation 1999;99:1767-73.

9 World Health Organisation. MONICA Manual version 1.1. Geneva: WHO, 1986.

10 ACC/AHA guidelines for the early management of patients with acute myocardial infarction. Circulation 1990;82:664-707.

11 Fuller JH, Shipley M, Rose G, et al. Mortality from coronary heart disease and stroke in relation to degree of glycaemia: the Whitehall study. BM 1983;287:867-70.

12 Scheidt-Nave C, Barrett-Connor E, Wingard DL, et al. Sex differences in fasting glycaemia as a risk factor for ischemic heart disease death. Am J Epidemiol 1991;133:565-76.

13 Gerstein HC, Yusuf S. Dysglycaemia and risk of cardiovascular disease. Lancet 1996;347:949-50.

14 Gerstein HC. Is glucose a continuous risk factor for cardiovascular mortality? Diabetes Care 1999;22:659-60. 
15 Bjornholt J, Erikssen G, Aaser $\mathrm{E}$, et al. Fasting blood glucose: an underestimated risk factor for cardiovascular death. Diabetes Care 1999;22:45-9.

16 Coutinho M, Gerstein HC, Wang Y, et al. The relationship between glucose and incident cardiovascular events. A metaregression analysis of published data from 20 studies of 95,783 indivuduals followed for 12.4 years Diabetes Care 1999;22:233-40.

17 Yudkin JS, Blauth C, Drury P, et al. Prevention and management of cardiovascular disease in patients with diabetes mellitus: an evidence base. Diabet Med 1996;13 (suppl): 101-21.

18 Sewdarsen M, Vythilingum S, Jialal I, et al. Prognostic importance of admission plasma glucose in diabetic and non-diabetic patients with acute myocardial infarction. Q J Med 1989;71:461-6.

19 O'Sullivan JJ, Conroy RM, Robinson K, et al. In-hospital prognosis of patients with fasting hyperglycaemia after myocardial infarction. Diabetes Care 1991;14:758-60.

20 Aronson D, Rayfield EJ, Chesebro JH. Mechanisms determining course and outcome of diabetic patients who have had acute myocardial infarction. Ann Intern Med 1997; 126:296-306.

21 Capes SE, Hunt D, Malmberg K, et al. Stress hyperglycemia and increased risk of death after myocardial infarction in patients with and without diabetes: a systematic overview. Lancet 2000;355:773-89.

22 Lakhdar A. The diagnosis of preexisting diabetes associated with acute myocardial infarction. Diabetes Care 1998;21:461.

23 Bellodi G, Manicardi V, Malavasi V, et al. Hyperglycaemia and prognosis of acute myocardial infarction in patients without diabetes mellitus. Am J Cardiol 1989;64:885-8.

24 Lakhdar A, Stromberg P, McAlpine SG. Pronostic importance of hyperglycaemia induced by stress after acute myocardial infarction. BM 1984:288:288

25 Vetter NJ, Strange RC, Adams W, et al. Initial metabolic and hormonal response to acute myocardial infarction. Lancet 1974;i:284-8.

26 Oswald GA, Smith CC, Betteridge DJ, et al. Determinants and importance of stress hyperglycaemia in non-diabetic patients with myocardial infarction. BM 1986;293:917-22

27 Ceriello A. Acute hyperglycaemia and oxidative stress generation. Diabet Med 1997; 14 (suppl):S45-9.
28 Lee TS, Saltsman KA, Ohashi H, et al. Activation of protein kinase $\mathrm{C}$ by elevation of glucose concentration: proposal for a mechanism in the development of diabetic vascular complications. Proc Natl Acad Sci USA 1989:86:5141-5.

29 Williams B. Glucose-induced vascular smooth muscle dysfunction: the role of protein kinase C. J Hypertens 1995;13:477-86.

30 Baumgartner-Parzar SM, Wagner L, Pettermann M, et al. Modulation by high glucose of adhesion molecule expression in cultured endothelial cells. Diabetologia 1995;38:1367-70.

31 Gilcrease MZ, Hoover RL. Examination of monocyte adherence to endothelium under hyperglycaemic conditions. Am J Pathol 1991;139:1089-97.

32 Sobel BE. Insulin resistance and thrombosis: a cardiologist's review. Am J Cardiol 1999;84:37-41.

33 Malmberg K, Ryden L, Hamsten A, et al. Effects of insulin treatment on cause-specific one-year mortality and morbidity in diabetic patients with acute myocardial infarction. DIGAMI myocardial infarction Study Group. Diabetes insulin-glucose in acute myocardial infarction. Eur Heart J 1996; 17:337-44.

34 Malmberg K, Norhammar A, Wedel H, et al. Glycometabolic state at admission: important risk marker of mortality in conventionally treated patients with diabetes mellitus and acute myocardial infarction: long-term results from the Diabetes and Insulin-Glucose Infusion in Acute Myocardial Infarction (DIGAMI) study. Circulation 1999;99:2626-32.

35 Sodi-Pallarés D, Ponce de León J, Bisteni A, et al. Potassium, glucose and insulin in myocardial infarction. Lancet 1969;i:1315-16.

36 Fath-Ordoubadi F, Beatt Ki. Glucose-insulin-potassium therapy for treatment of acute myocardial infarction: an overview of randomized placebo-controlled trials. Circulation 1997;96:1152-6.

37 Diaz R, Paolasso EA, Piegas LS, et al. Metabolic modulation of acute myocardial infarction. The ECLA (Estudios Cardiologicos Latinoamerica) Collaborative Group. Circulation 1998;98:2227-34.

38 Mak KH, Topol EJ. Emerging concepts in the management of acute myocardial infarction in patients with diabetes mellitus. J Am Coll Cardiol 2000;35:563-8. 